\title{
Facial and Multiple Mandibular Traumatic Injuries: Accidental Case Study
}

\author{
Sandeep Kumar ${ }^{1}$, Madhukar Saxena ${ }^{2, *}$, Shubhangi Chaturvedi ${ }^{2}$, Dinesh \\ Raj Modi ${ }^{2}$
}

\begin{abstract}
${ }^{1}$ Bakson Homoeopathic Medical College \& Hospital, Knowledge Park Masjid, Plot No. 36 B, Phase-I, Greater Noida, Uttar Pradesh -201306 and O.P. Chaudhary Hospital and Research Center, Raibareli Road, Sector 1, Chaudhary Vihar, Lucknow 226025, Uttar Pradesh, India;

${ }^{2}$ Department of Biotechnology, Babasaheb Bhimrao Ambedkar University (A Central University) Vidya Vihar, Rai Bareilly Road, Lucknow- 226025, Uttar Pradesh, India.
\end{abstract}

\section{ARTICLE INFO:}

Received: 18 Jun 2020

Accepted: 22 Sep 2020

Published: 30 Dec 2020

\section{Corresponding author *} Madhukar Saxena, Department of Biotechnology, Babasaheb Bhimrao Ambedkar University (A Central University) Vidya Vihar, Rai Bareilly Road, Lucknow-226025, Uttar Pradesh, India.

E Mail: madhukarbio@gmail.com

\begin{abstract}
:
Background: In cranio-maxillofacial traumas (CMT) the most common and severe damage is Mandible disruption. This result in chronic health issues because of CMT risk of unhealthy state of body has been increased which is related to deformities in face which give rise to many operational limitations and many changes in appearance of damaged face.

Objective: To analyze the facial and mandibular damage in accidental injuries and to focus on correct procedure for complete recovery of patients.

Results: The damage has occurred with huge amount of energy that causes almost complete tearing of mandibular bone. Disruption of facial and mandible bone in such a way causes many injuries including removal of the skin and subcutaneous tissues of the mandible that distract and affects blood vessels, muscles and nerves of associated area.

Conclusion: In this case report we have discussed about a car accidental case having severe mandible damage. Importantly we focus on correct procedures for stabilization of patient, appropriate control of damage and specifically reconstruction of face in better ways.
\end{abstract}

Keywords: Mandibular Injuries, cranio-maxillofacial traumas, Accident, subcutaneous tissue, reconstruction.

\section{INTRODUCTION}

As the cases of road accidents have been increased so rapidly in the last decades, that the CMT is becoming an major health issue. As reported many structures have been damaged in road accident or injuries but mandible damage is the most common and is closely involved to CMT, as lots of cases analyzed it's been concluded on the basis of observation of damaged features that anatomy of face has damaged severely and many face projection associated problems arises, that somehow relatable with trauma. On a survey worldwide it has observed that specifically car and motorcycle accidents are main reasons for CMT, because structures as mandible bone are very less prone to damages easily such chronic damages resulted from a high-energy trauma to body that ultimately fractures mandible [1].
However, jaw damage is considered as the rare event observed in many cases of accidental face avulsions. The most common facial fractures seen in accidental patients are Mandibular fractures and the incidence of it in children is around $20-50 \%$ [2]. The most common mandibular fractures are the condylar region, symphysis, angle and body [3-5]. A complete scanning of the body is mandatory in suspected mandibular traumatic injuries. The condylar region (round prominence at the end of a bone) should be carefully examined for any evidence of facial and mandibular fracture having pain, restricted movement, deviation, crepitus and trismus [6]. Panoramic or posteroanterior mandible radiographs is recommended for the diagnosis, or if possible by cone beam computed tomography (CBCT) radiographs is highly recommended. The main focus in all types of mandibular fractures is the restoration of function while minimizing the side effects on mandibular growth. The exact location of damage during accidents has been recognized by the force direction and keen analysis of mechanism of injury 
International Journal of Pharma Research and Health Sciences, 2020; 8 (6): 3262-3264

that also reveals patterns of fractures. Many factors additionally help in determination of characteristics of fracture and their location such as presence or absence of teeth, patient's age, analysis of previous disease history of patient and properties of causative agents involved in damage. Despite of the fact, all this bone lesions severity and increase in the morbidity rate with high number of unusual fractures are all results of complex mechanism of causative agents on bone lesions, which requires highly stable therapeutic approaches. Major characteristics of mandible disruption involves separation of skin and subcutaneous tissue of mandible bone, that intensely affects fascia, muscles, surrounding blood vessels and nerves that all arises

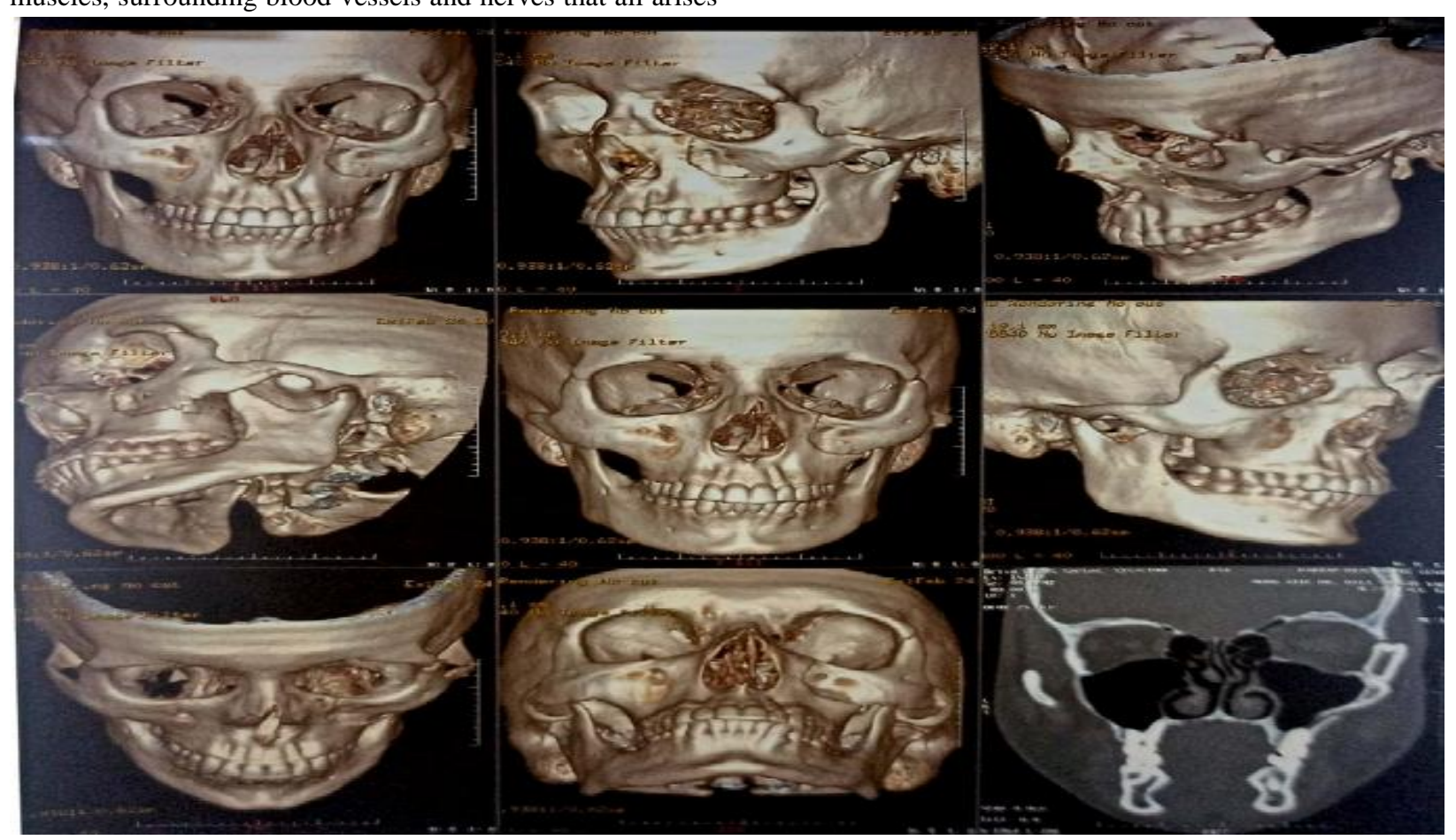

Fig 1: Cone beam CT views showing the fractures in the mandibular region

\section{CASE PRESENTATION}

A healthy 35 year old man was referred to the emergency clinics of Dr. O. P. Chaudhary Hospital and research Centre, following a severe facial trauma as a result of automobile accident. He complained of severe pain in his jaw and was unable to open his mouth. Initial anthropometric and physical examination showed abrasions and lacerations on the facial skin including lips. Limited opening of the mouth and lateral deviation of the mandible toward the right side on mouth opening were examined. Intraoral examinations predict a missing maxillary left lateral incisor and subluxation of his maxillary left central incisor. CBCT examination revealed a nondisplaced mandibular body fracture and a unilateral medially displaced subcondylar fracture on the right side (Figures 1). The patient was referred to maxofacial orthopedic Department for further follow up treatment after primary analgesics and antibiotics prescription. by an complex high energy trauma $[1,6]$. The entire treatment protocol that is supported by or approved by advanced trauma life support(ATLS) protocol, involves and ensure crucial management of airways followed by cervical spine protection and hypovolemic shock protection, that ultimately helps in cure and reconstruction of the fractures. Following article has presented many cases of mandibular damages that are caused due to car accidents. We specificaly emphasize on the proper management and stabilization of pateint's airways, control of damage and reconstruction of face. 
International Journal of Pharma Research and Health Sciences, 2020; 8 (6): 3262-3264

to the mandibular and mental nerves in such kind of mandibullar injuries $[6,10,11]$.

\section{CONCLUSION}

In adult patients, the fractures have a lower potential for remodeling as well as in condylar fractures because dislocation have less predictability in relation to adaptation and bone remodeling. Thus, the need for surgical reduction of the fracture is mandatory to replace the condyle within the articular fossa. Usually the surgical reduction of condylar fractures is a delicate procedure due to the presence of several anatomical structures in the region. It has been observed that the patient showed no complications after 3 year. Radiographic examination revealed that the remodeling of the condyle was very good and that the function was within normal ranges. Proper precaution and care should be taken care of by the patient.

\section{REFERENCES}

1. Rezende RLS, Bonjardim LR, Neves ELA, et al. Oral Health, Temporomandibular Disorder, and Masticatory Performance in Patients with Charcot-Marie-Tooth Type 2. The Scientific World Journal 2013; 2013: 1-8.

2. Smartt JM, Low DW and Bartlett SP. The pediatric mandible: II. Management of traumatic injury or fracture. Plast Reconstr Surg 2005; 116: 28e-41e.

3. Glazer M, Joshua BZ, Woldenberg Y and Bodner L. Mandibular fractures in children: analysis of 61 cases and review of the literature. Int $\mathrm{J}$ Pediatr Otorhinolaryngol 2011; 75: 62-4.

4. Thoren $\mathrm{H}$, Iso-Kungas $\mathrm{P}$, Iizuka $\mathrm{T}$, Lindqvist $\mathrm{C}$ and Tornwall J. Changing trends in causes and patterns of facial fractures in children. Oral Surg, Oral Med, Oral Pathol, Oral Radiol Endodontol 2009; 107: 318-24.

5. Smith DM, Bykowski MR, Cray JJ et al. 215 mandible fractures in 120 children: demographics, treatment, outcomes, and early growth data. Plast Reconstr Surg 2013; 131: 1348-58.

6. Aizenbud D, Hazan-Molina H, Emodi O and Rachmiel A. The management of mandibular body fractures in young children. Dent Traumatol 2009; 25: 565-70.

7. Carinci F, Arduin L, Pagliaro F, Zollino I, Brunelli G and Cenzi R. Scoring mandibular fractures: a tool for staging diagnosis, planning treatment, and predicting prognosis. J Traum Injr, Infect Critic Care 2009; 66: 215-9.

8. Lindah L. Condylar fractures of the mandible. Classification and relation to age, occlusion, and concomitant injuries of teeth and teeth supporting structures, and fractures of the mandibular body. Int $\mathbf{J}$ Oral Surg 1977; 6: 12-21.

9. Park SS, Lee KC and Kim SK. Overview of mandibular condyle fracture. Arch Plast Surg 2012; 39: 281-3.
10. Kaban LB. Diagnosis and treatment of fractures of the facial bones in children 1943-1993. J Oral Maxillofac Surg 1993; 51: 722-9.

11. Noleto JW, Leao EI, Braga CL, Yang S and Sardow A. Conservative approach of condylar fracture in a child by the use of rubber elastics: 7-year follow-up. J Dentist Childr 2011; 78: 148-53.

\section{Conflict of Interest: None Source of Funding: Nil}

